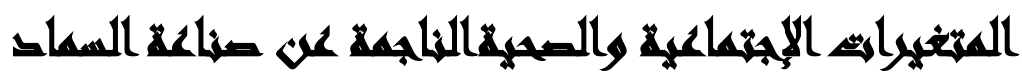

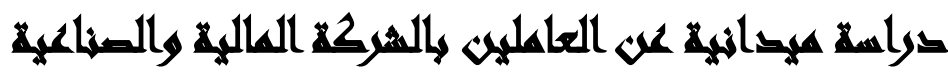 \\ سمات هنميات- أسيوط}

\section{[1r]}

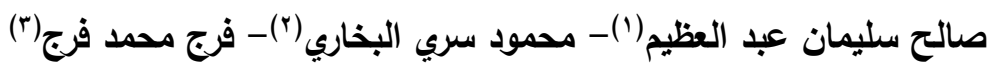

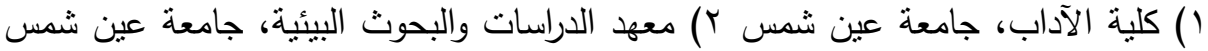

r) جهاز شئون البيئة

\section{المستخلص}

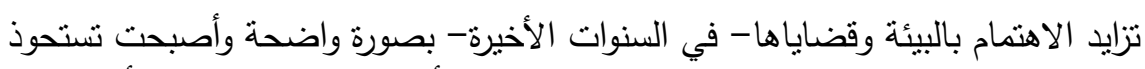

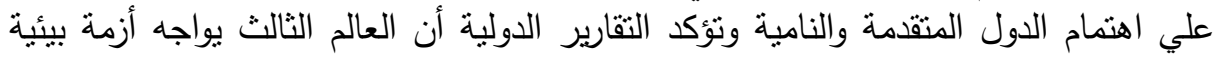

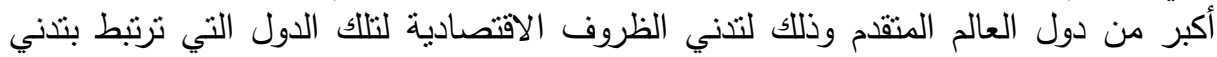

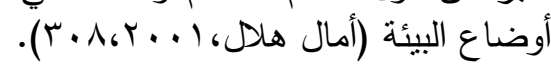

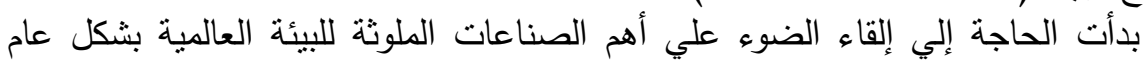

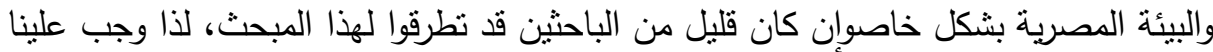

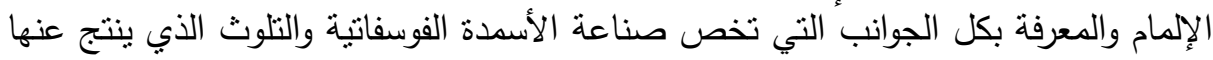

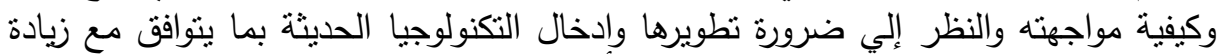

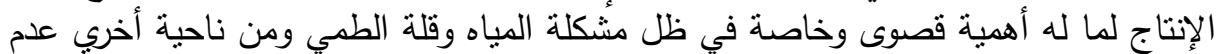

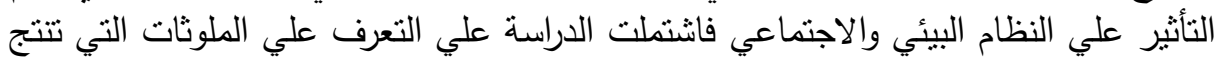

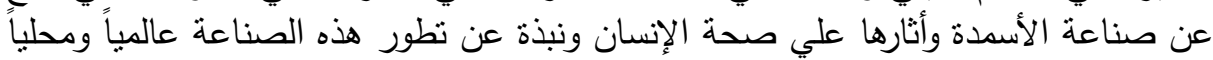

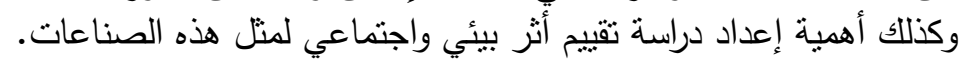

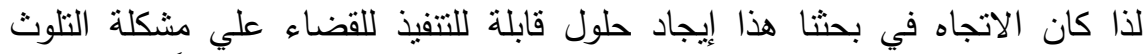

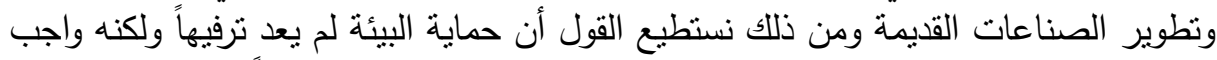

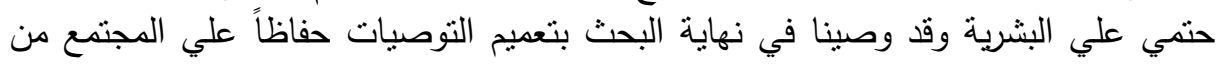
إن الهدف الرئيسي لهذا البحث هو بيان المتغيرات الإجنماعية والبيئية الناجمة عن التلوث البيئي البني

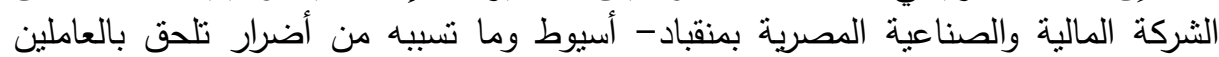
داخل المنشأة والقاطنين بالقرب منها. 


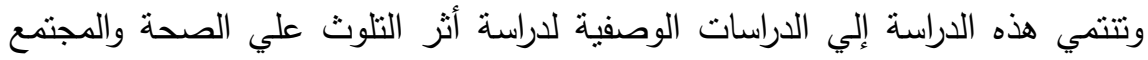

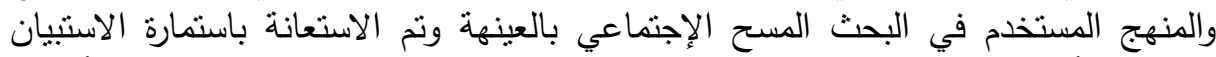

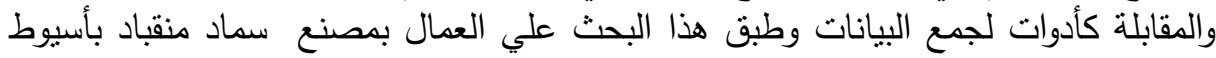

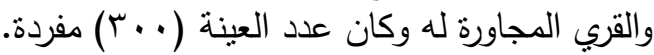
وتتلخص نتائج البحث فيما يلي:

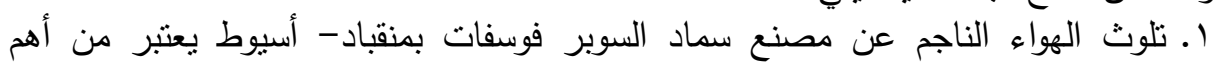

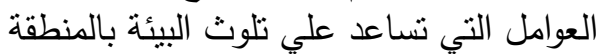
r r. كثفت الدراسة عن انخفاض قيمة المحافظة علي البيئة

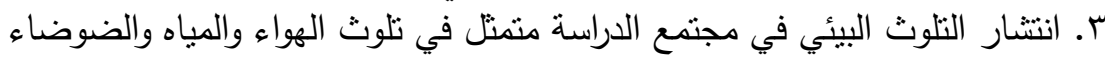

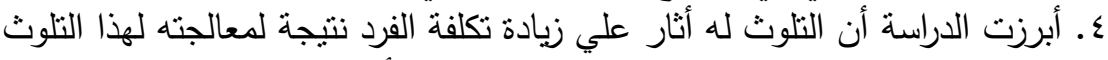

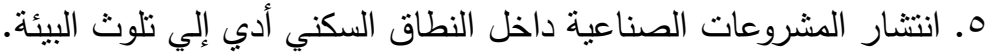

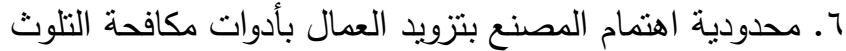

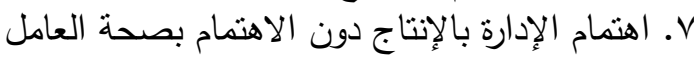

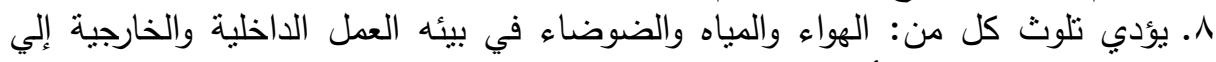

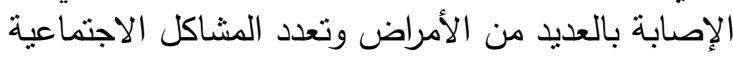

\section{anadl}

إن حياة الإنسان منذ أن هبط علي الأرض نرتبط بالبيئة التي وجد فيها كما ارتبطنطوره

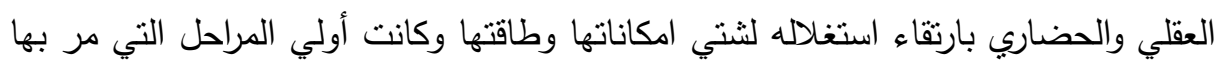

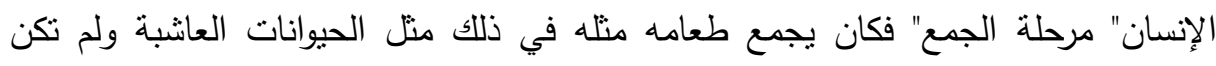
تتطلب منه تلك المرحلة مشقة التفكير أو بذل المجهود. وتطور فكر الإنسان من الممارسة والتجربة ودخل مرحلة الرعي واستئناس الحيوان والزراعة البدائية وكانت هذه المرحلة داعمة لقدراته العقلية فيما يختص بدراسة ولهن الأحوال الطبيعية والظواهر البيئية وما صاحبها من تحولات حضارية وإجتماعية بالغة الأهمية. وهكذا لإنها

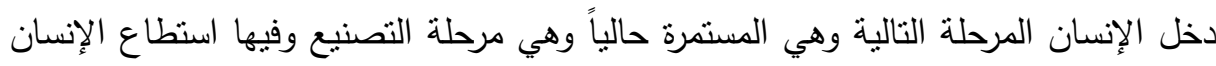

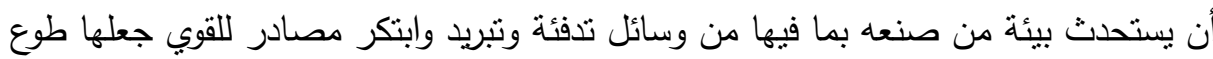

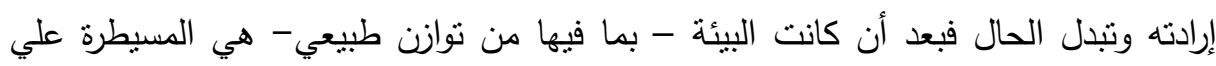


سلوك الإنسان أصبح الأمر الأن في يد الإنسان فهو المالك للزمام (محمد نبهان سويلم .(1) . 1999

وتعتبر صناعة الأسمدة الفوسفاتية من أهم الصناعات الكيماوية الملوثة والتي تحتوي مصانعها محطات معالجة المياه وتوليد الطاقة والغلايات.

\section{مئهill}

بدأت الحاجة إلي إلقاء الضوء علي أهم الصناعات الملوثة للبيئة العالمية بشكل عام

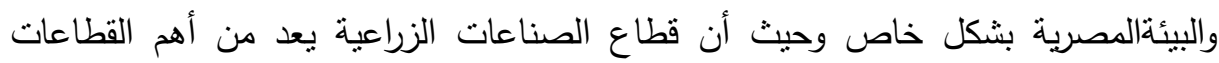
الصناعيةالرائدة في دعم الاقتصاد الوطني حيث يعمل هذا القطاع من خلال استراتيجيات

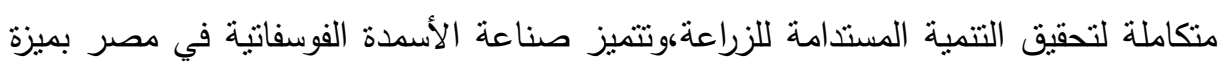

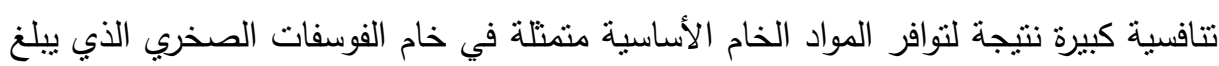

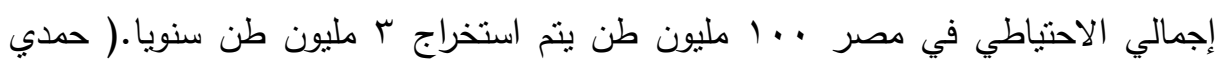

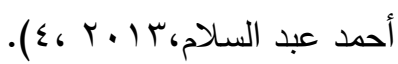

وتعد صناعة الأسمدة الفوسفاتية من الصناعات الملوثة في مصر وعلي الرغم من المحاولات الجادة خلال السنوات الماضية لتحسين الظروف البيئة بهذه الصناعة إلا أنه لازالت التهاء

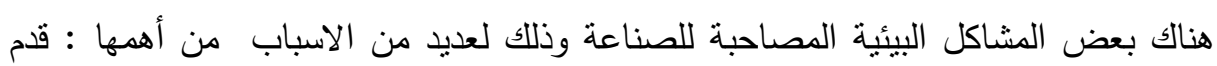
التكنولوجيا المستخدمة في الإنتاج نتيجة لأن هذه المصانع كانت تحت مظلة قطاع الأعمال

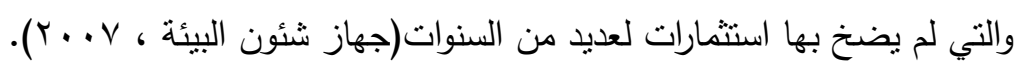

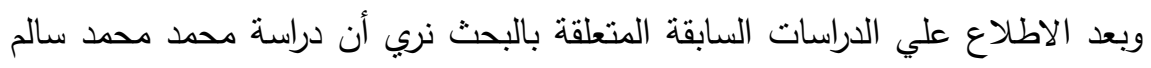
وكانت تهدف إلي القاء الضوء علي مظاهر التلوث الصناعي وأثناره الصحية علي البيئة والتعرف علي مظاهر التلوث ومصادره وأنواعه وعلي مدي انتشار التلوث البيئي وإبراز دور

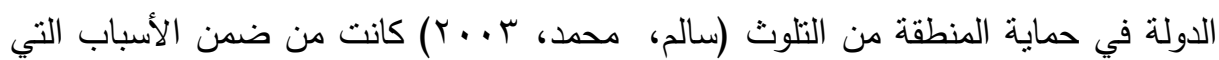
أكدت الحاجة إلي هذا البحث. 


\section{تمساؤلايش السراسة}

ا ـ مالآثارالاجتماعية والبيئية الناتجة عن صناعه السماد؟ r. ما المتطلبات اللازمة لتجنب السلبيات ووضع تصور لتلافيها؟ r. ما مدي خطورة تعرض سكان المنطقة المحيطة لملوثات صناعة السماد بمنقباد ؟ ء. هل توجد علاقة بين ملوثات مصنع السماد بمنقباد والجانب الصحي لسكان المنطقة

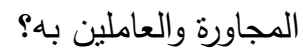

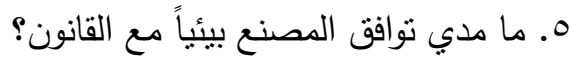

\section{أهمية المبهث}

تتقسم إلي أهمية علمية وأخري تطبيقية: - الأهمية العلمية: وهي إثراء الدراسات المتعلقة بالبيئة وعلم الاجتماع البيئي والصناعي الهيل - الأهمية التطبيقية: الخروج من البحث بتوصيات ومقترحات تكون ذات تأثير فعال علي

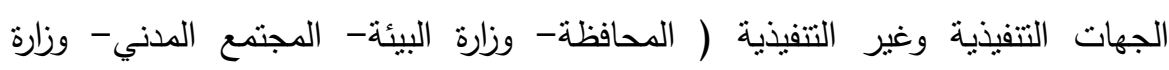
الصحة) للحفاظ علي البيئة وحياة الإنسان المصري مما ينعكس إيجابياً علي الإنتاج

$$
\text { وازدهار الاقتصاد الوطني. }
$$

\section{مهزاهيه القراسما}

بيئة العمل: تثير البيئة إلي تلك الصفات المحيطة بالفرد ويمنل العمل جزءاً مهماً من البيئة التي تؤثر في تفسير شخصية الفرد فلكل عمل شروطه ومتطلباته التي تلزم العاملين فيها

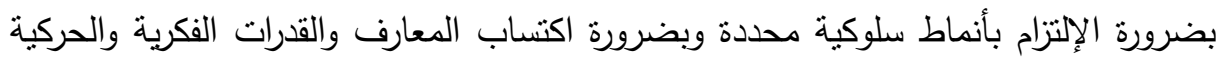

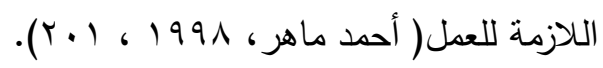
وشرح " مصلح الصالح" مفهوم البيئة علي أنه: كل العوامل الطبيعية والمصادر الخارجية التي يعيشها الثخص أو الجماعة معايشة حقيقية ويستشعرون وجودها دونما معايشة. (مصلح

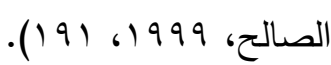


تعرف البيئة علي أنها الإطار الذي يعيش فيه الإنسان، ويحصل منه على مقومات

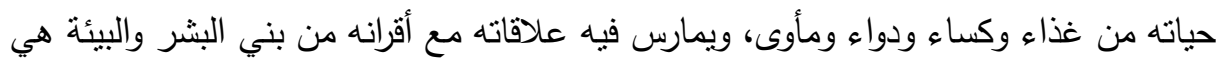

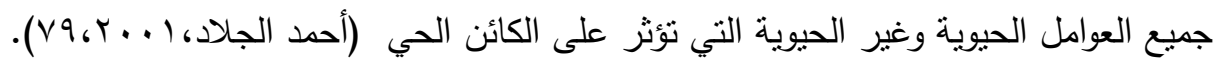
فيقصد ببيئة العمل جميع مكونات العمل من تتظيم وخدمات وعوائد مالية واجنماعية ومكانيه، وتتقسم البيئة إلي قسمين:

\section{- بيئة داخلية. بيئة خارجية.}

البيئة الداخلية: هي كل ما يحيط بالفرد داخل المصنع أو المنشأة من ظروف فيزيقية وفنية

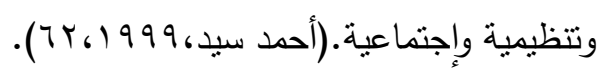

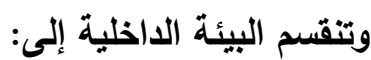

بيئة مادية: وهى عبارة عن ترتيب وتتظيم العمل والمعدات بشكل يؤثر إيجابياً على الأفراد . بيئة اجتماعية: وتتعلق بالتفاعل بين الأفراد واحترام مبادئ وقواعد السلوك والقواعد والقوانين

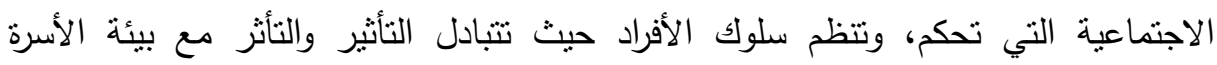

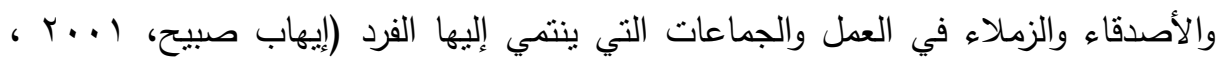
$\cdot(r \cdot:)^{\prime}$ ومما هو جدير بالذكر أن هناك تعريفاً شاملاً لبيئة العمل بركز على أن بيئة العمل جزء من البيئة العامة ذو التأثير المباشر على أهداف المنظمة، وتتكون من العملاء والموردين

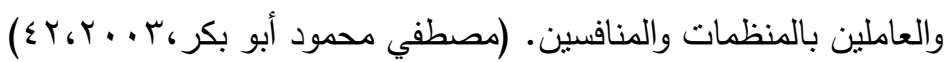
يرى الباحث أن بيئة العمل يقصد بها جميع مكونات العمل من نتظيم ولوائح وثقافة

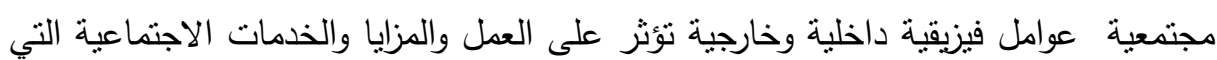
تقدم للعاملين. من هذا المفهوم يمكن تقسيم بيئة العمل إلى أربعة أقسام هي:

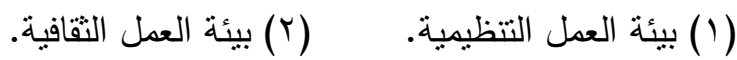

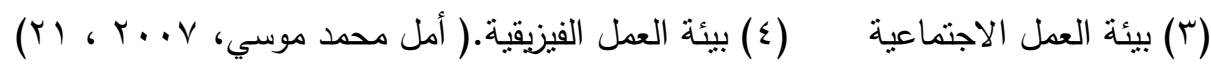


السماد: يُعرف: بأنه المادة العضوية أو الكيميائية (غير العضوية) تضاف للتربة لتعويض فقد عنصر غذائي واحد أو أكثز علي صوره ميسرة للنبات لرفع الإنتاجية. (عصام محمد

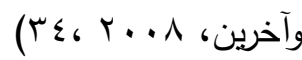
أنواع الأسمدة: تقسم من حيث نركيبها الكيميائي وتكوينها وطرق إضافتها وتفاعلاتها بالتربة، ويمكن تصنيف الأسمدة إلي مجموعتين، الأسمدة المعدنية والأسمدة العضوية. أولاً: تقسيم الأسمدة المعدنية إلي أسمدة بسيطة وأسمدة مركبة.

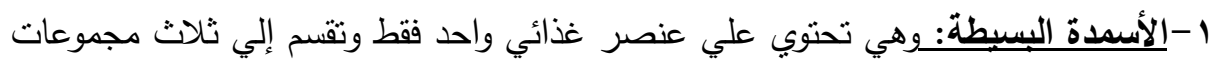
رئيسية.

r- الأسمده المركبة(العضوية): تمد النبات بالعناصر السمادية الأساسية- ومنها السباخ

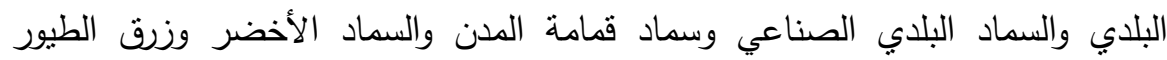

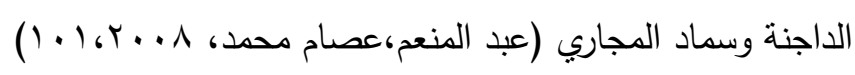

الأمن الصناعي: ويعرف الأمن الصناعي بأنه جميع الأنشطة الهادفة إلى حماية الأفراد

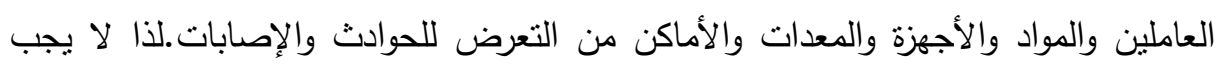
الاهتمام بالجوانب المادية فقط، بل يجب الاهتمام بالجوانب التنظيمية التي يمكن أن تلعب دوراً

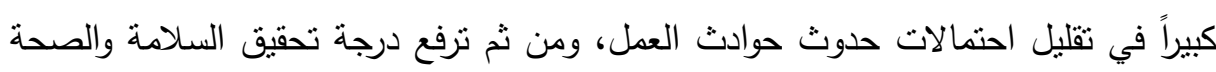

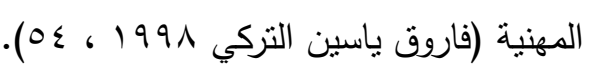

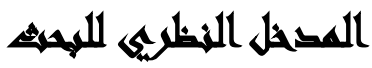

نظرية الخطورة البيئية: هذه النظرية نربط المشاكل البيئية بالتتمية والثورة الصناعية ويمكن ايجاز هذه النظرية في الآتي: أ- أدت الثورة الصناعية وما ارتبط بها من سياسات نتوير عديدة إلي ظهور العديد من المشاكل أو الخطورة البيئية مثل نقب الأوزون والصوبة الزجاحية والتغيرات المناخية

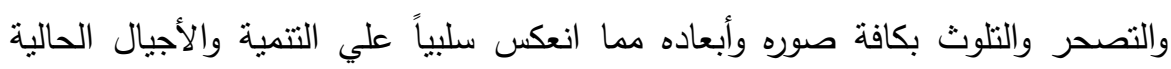


وأيضاً علي حق الأجيال القادمة في بيئة نظيفة وتتميز هذه المشاكل بالعالمية دون التفرقة بين دولة نامية أو متقدمة وأصبجت النظرة إلي العالم الواحد من خلال عولمة مشاكل البيئة هي التي تحكم علاقة الإنسان اليوم في ظل العولمة

ب- ويركز ألرك بك علي أن الخطورة البيئية العالمية معظمها يرتبط بالصناعة والتكنولوجيا

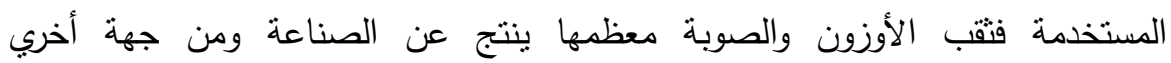
فالتكنولوجيا النووية أدت لانفجار مفاعل تشرنوبل في روسيا ، كل هذا أدي لبداية الإهنمام بالبيئة وظهور المؤسسات والحركات البيئية علي مستوي العالم ومر ذللك بمرحلتين هما: المرحلة الأولي كان التركيز علي البيئة الفيزيقية وفي الثانية امتد الإهتمام للبيئة الإجتماعية( Ulrik Beck,1992,39).

ج- ويتفق بوكنان وجيدنز مع بك في مسئولية التكنولوجيا بوجه عام والتكنولوجيا الصناعية بوجه خاص عن معظم المشكلات البيئية الحديثة والتي انعكست علي البيئة الطبيعية وعلي الإنسان أيضاً من خلال انعكاس هذه المشكلات والملوثات البيئية علي صحة الإنسان في شكل تسمم وتلوث وأمراض سرطانية متزايده ومن هذا تتواصل الدائرة وتكتمل

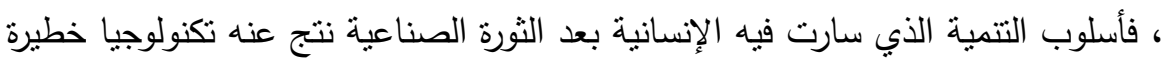

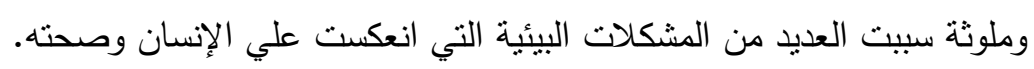
تعليق: هذه النظرية ترجع معظم مشكلات البيئة للتصنيع والتكنولوجيا الصناعية وهذا يمنل السبب الرئيسي لحدوث تلوث بيئي بالإضافة إلي العوامل الطبيعية الأخري ، فمعظم

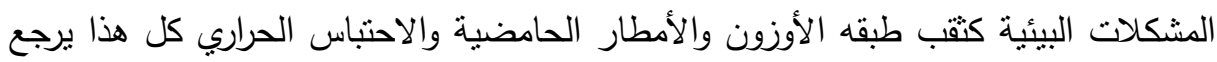
إلي استخدام التكنولوجيا بطريقة غير سليمة تحدث أضراراً خطير بالبيئة وبصحة الإنسان. 


\section{السرواسايت السابري}

الاراسات المتعقةة بالبعد الاجتماعي-

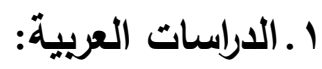

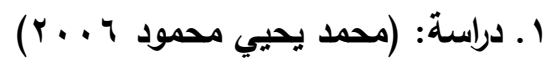

أهدف الاراسة:

- تهذف الدراسة إلي التعرف علي أثز المتغيرات الديمجرافية في وقوع إصابات عمل

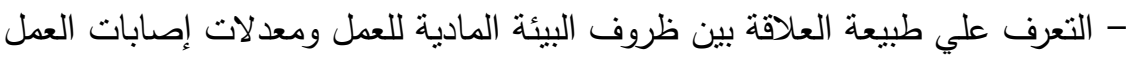
نتائج الاراسة:

- يعاني مجتمع البحث من مشكلات تتمثل في تزايد عدد أفراد الأسرة وقلة عدد غرف المسكن. - اتضح أن نسبة كبيرة من العمال لا نستخدم أدوات الأمن الصناعي بجانب نقص التدريب.

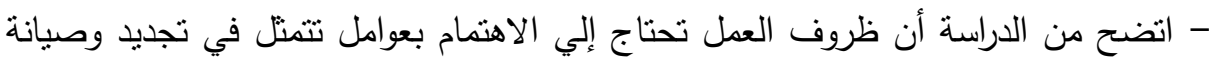

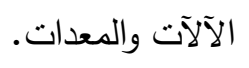

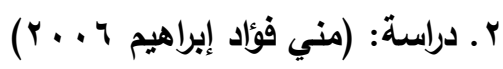

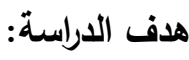

- التعرف علي وعي العاملين بمصانع الغزل والنسيج بأسباب المشكلات البيئية والتعرف علي الآثار السلبية المترتبة علي المشكلات البيئية الني نواجه العاملين بمصانع الغزل والنسيج.

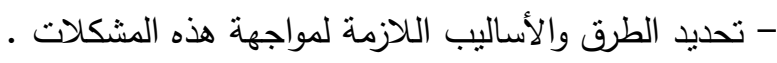
نتائج الاراسة: - محدودية اهتمام المصنع بأدوات مكافحة التلوث واهتمام الإداره بالإنتاج دون الاهتمام بصحة العامل - يؤدي تلوث كل من "الهواء والماء والضوضاء داخل المصنع إلي الاصابه بالعديد من الأمراض والمشاكل الصحية والاجتماعية. 


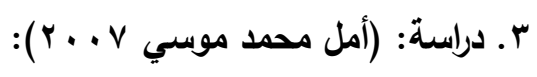

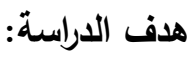

- التعرف علي أثز المتغيرات الاجتماعية في دعم الروح المعنوية لدي العاملين و نأثثر هذه

المتغيرات علي إنتاجية الفرد كماً وكيفاً.

- التعرف علي المشكلات الاجتماعية والبيئية التي تواجه الإدارة العليا والعاملين.

نتائج الاراسة:

- تحفيز العاملين وإعطاؤهم حقوقهم وتقوية العلاقات بين العاملين والقيادات.

- أوضحت أن هناك مجموعة من المشكلات التي تواجه العاملين والإدارة.

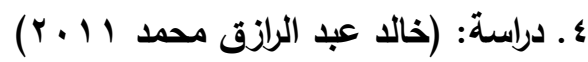

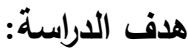

- تهدف الدراسة إلي معرفة أسباب التلوث والمشكلات الناجمة علي صحة العامل . - معرفه تأثثر تلوث البيئة علي جوانب الحياة الإجتماعية والكثف عن جهود الدولة في

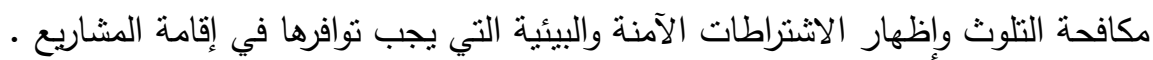

نتائج الاراسة:

- وجود تلوث أخلاقي كالسلبية واللامبالاة وعدم اكتراث الناس بالقوانين.

- التلوث له أثار علي زيادة تكلفة الفرد نتيجة لمعالجته لهذا التلوث.

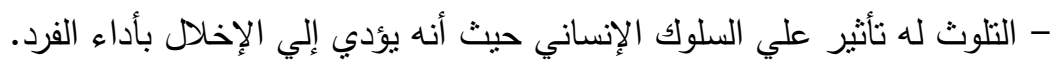

- انتشار المشروعات الصناعية داخل النطاق السكني أدت الي تلوث البيئة.

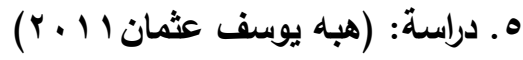

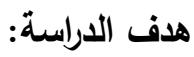

- للاراسة هدف رئيسي وهو الكثف عن التغيرات في بعض العادات الاجتماعية والقيم البيئية ويندرج تحته أهدافاً فرعية وهي معرفه أثر التغيرات في قيمة المحافظة علي الهواء من فئن

التلوث - الكثف عن أثر التغيرات في قيمة مواجهة المشكلة السكانية. 
- قيمة المحافظة علي الهواء من التلوث قد تغيرت داخل مجتمع الدراسة. - حدوث انخفاض في قيمة المحافظة علي الأراضي الزراعية.

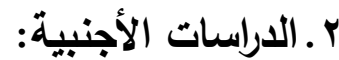
ا. ـدراسة: (Carole Boraiko2003): استهدفت هذه الدراسة تقييم الأثر البيئي لملوثات الهواء الناجمة عن عمليات التصنيع والتي ينولا عنها بعض الغازات والأبخرة والحرارة داخل بيئة المصنع وما يترتب عليها من مخاطر مهنية داخل بيئة العمل. نتائج الدراسة: تلوث البيئة يؤثر علي العمال من حيث عددهم وقدرتهم علي الإنتاج. r.دراسة: (Leland Cole Brian 2003): استهدفت هذه الدراسة تحديد الأبعاد الإجتماعية للمشكلات الصحية للعاملين في المصنع والطرق والأساليب التي يجب علي العاملين في المخلفات الخطرة اتباعها للوقاية والتأمين من مخاطر العمل والمهنة.

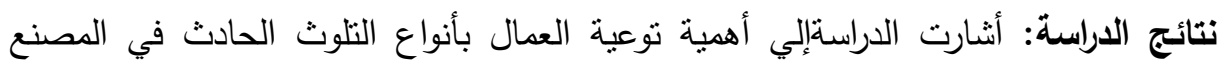
وطرق الوقاية منها وضرورة مشاركة العمال في التدريب والتعلم الفعال علي كيفية مواجهة

$$
\text { المشكلات البيئية والصحية. }
$$

r. دراسة: (2003, Cote,Heslin): استهدفت هذه الدراسة تحقيق هدف رئيسي وهو :

$$
\text { (شعور الفرد بالرضا الوظيفي قد يؤدي إلي الانتماء التنظيمي) • }
$$
نتائج الدراسة:وجود علاقةارتباطية طردية بين الرضا الوظيفي والانتماء التنظيمي. ع. دراسة: (Lawrence Radican Francis 2004): استهدفت الدراسة معرفة تأثير

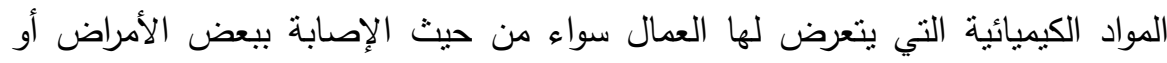
تؤدي إلي الوفاة. نتائج الدراسة: التعرض للهيدروكربون يزيد من مخاطر الإصابة بأمراض الكلي المزمنة وزيادة 


\section{إجباءlis المهنه}

نوع الدراسة: تتنمي هذه الدراسة إلي الدراسات الوصفية لدراسة أثز التلوث علي الصحة والمجتمع. المنهج المستخدم: ولقد اختار الباحث في هذا البحث المسح الاجتماعي بالعينة.

\section{هجالاهي التواسلة}

ا - المجال المكاني: طبقت هذه الدراسة علي العمال بمصنع سماد منقباد بأسيوط والقري المجاورة له

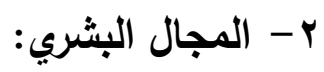

- عينة من عمال المصنع ذات الثأثير المباشر للتلوث وعددهم (10 (1) فرداً. - المسئولين بالجهات الحكومية سواء في الحكم الدحلي أو وزارة البيئة أو وزارة الصحة فردا. وعددهم (· (1) أفراد. - - عينه من أهالي القري المجاورة للمصنع(جزيرة الاكراد- قرية منقباد) وعددهم ( (1) فرداً. ب- المجال الزمني: استغرقت فترة جمع البيانات مدة ^ شهور تقريباً بدءاً من

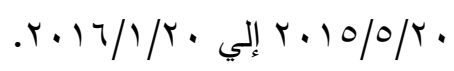

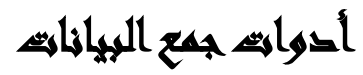

استخدمت مجموعة من الأدوات التي فرضتها طبيعة المنهج المستخدم ونوع الدراسة من

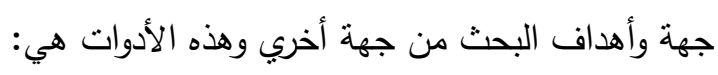

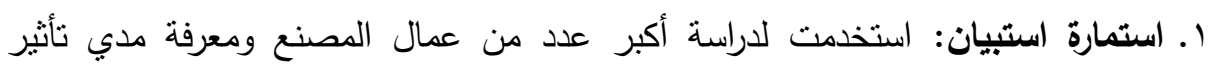

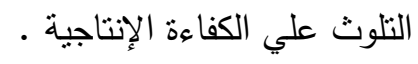

r. استمارة استبيان: وذلك لدراسة عدد الكبر من سكان المنطقة المجاورة للمصنع لمعرفة مدي التضرر الناتج عن نواجد الصناعات الثقيلة بالقرب من المناطق السكنية.

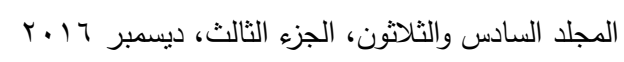


r. دليل مقابلة: وذللك مع المسئولين بالجهات الحكومية التي لها دور رقابي علي المصنع.

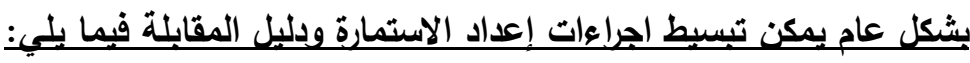
1. - تحديد الهدف العام من الاستمارة. ب- تقسيم الهدف العام إلي أهداف فرعية. r. يتم تقسيم الهدف الفرعي إلي أهداف فرعية أخري.

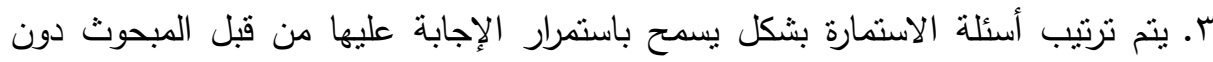
ملل.

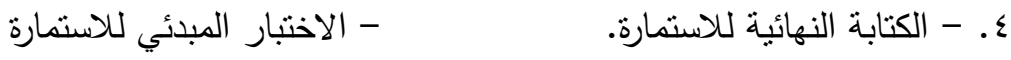

$$
\begin{aligned}
& \text { ه. تعديل الأسئلة وفقاً لما يظهر من الاختبار المبدئي. }
\end{aligned}
$$

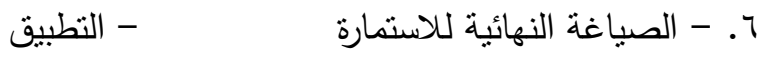

عند تصميم كل استمارة تم اتباع مجموعة من الخطوات هي: الخهارة

أ- الإطلاع علي الدراسات والبحوث السابقة والكتابات النظرية

ب- تحديد الأسئلة الرئيسية لكل استمارة ويبلغ عدد الأسئلة في دليل المقابلة (• (1) أسئلة وعدد الأسئلة في استمارتي الاستبيان(• ع) و (rr) سؤال.

ت- صياغة العبارات الدالة علي كل مؤشر من الأسئلة السابقة.

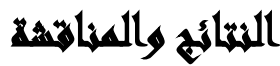

1 - تحليل النتائج: نم الإجابة على نساؤل: ما هي المتغيرات الاجتماعية والبيئية الناجمة

$$
\text { عن صناعة السماد من خلال إجابات العاملين بالمصنع كالتالي: }
$$

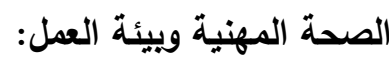

\begin{tabular}{|c|c|c|}
\hline$\%$ & 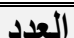 & الخدمات الصحية المتوفرة فَ المصنمع \\
\hline $0, r$ & $\overline{\Lambda \Lambda}$ & اجزخانات صحيةة \\
\hline$Y, \cdot$ & $r$ & مستشفي \\
\hline $1, \mu$ & $\bar{r}$ & وحدة صحية \\
\hline$V \leq, \cdot$ & 111 & اطباء متخصصون \\
\hline$T \varepsilon, V$ & rY & آكثُ من خدمةً \\
\hline
\end{tabular}

جدول(1): التكرارات والنسب المئوية لعينة الدراسة تبعاً لمتغير الخدمات الصحية المنوفرة في

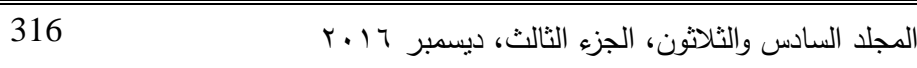


من الجدول السابق لإجابات عينة الدراسة على متغير الخدمات الصحية المتوفرة في المصنع ينبين أن (111) من أفراد العينة وهو ما نسبته (1) (1) من إجمالي أفراد البحث

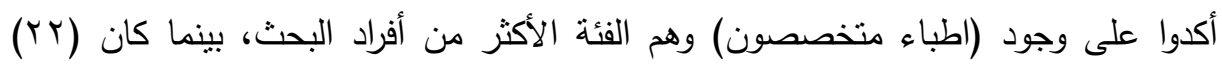

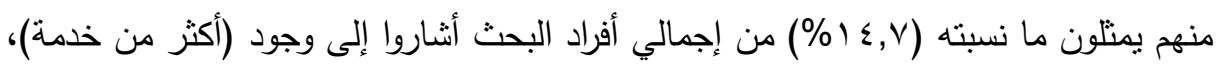

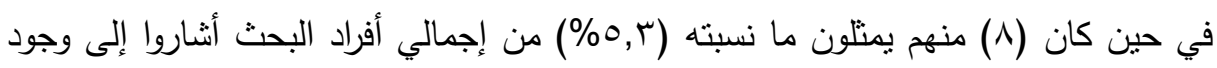

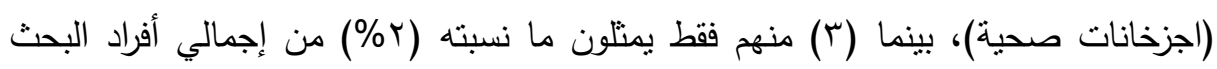

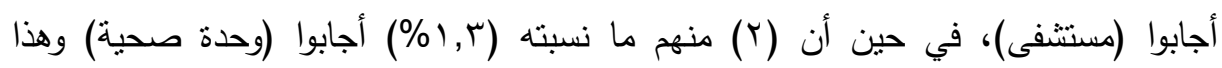
يوضح أن الخدمات الحكومية المدعومة غير منوفرة بقدر كاف بمنطقة البحث ولكن انتشار القطاع الخاص المتنتل في العيادات الخاصة واضح من خلال إجابة المبحوثين. للإجابة على التساؤل: ما خطورة التعرض لملوثات المصنع تعرضاً مباشراً داخل الدصنع أو خارجه؟ من خلال إجابات عينة الدراسة على الأسئلة التالية: تلوث البيئة: جدول(ץ): التكرارات والنسب المئوية لعينة الدراسة تبعاً للتساؤل يا ترى انت شايف فيه تلوث بالمنطقة؟

\begin{tabular}{|c|c|c|}
\hline$\%$ & العدد & المتغيرات \\
\hline$q \varepsilon, V$ & $1 \leqslant Y$ & نعر \\
\hline $0, r$ & $\Lambda$ & $\gamma$ \\
\hline
\end{tabular}

يتضح من الجدول السابق لإجابات عينة الدراسة على التساؤل أنت شايف فيه تلوث

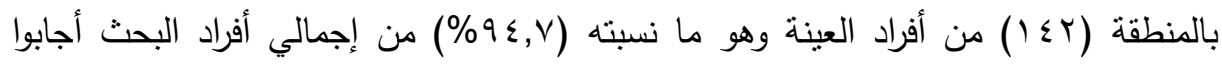

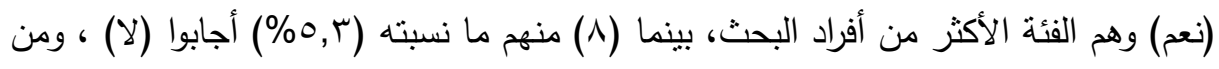

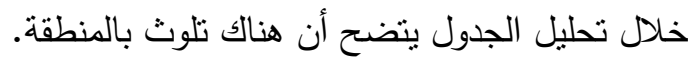

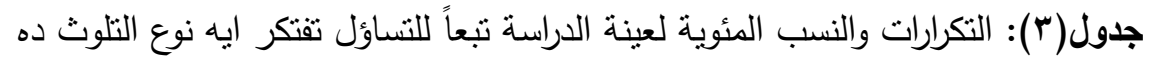

\begin{tabular}{|c|c|c|}
\hline$\%$ & العدد & المتغيرات \\
\hline$\varepsilon \cdot, \cdot$ & 7. & تلوث هواء \\
\hline 17,8 & ro & تلوث مياه \\
\hline$I Y, V$ & 19 & تلؤث تربية \\
\hline$r \cdot, V$ & $\varepsilon 7$ & تلوث ضوضائى \\
\hline
\end{tabular}


من الجدول السابق لإجابات عينة الدراسة عن نوع التلوث أجاب (• (؟) من أفراد العينة

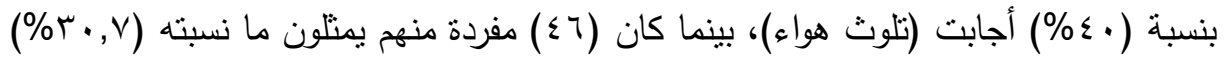

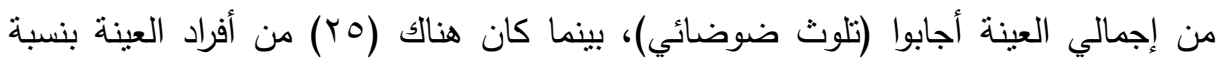

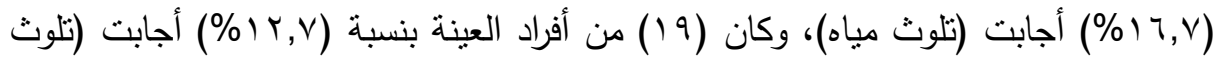
تربة) ، وهكذا نري أن تلوث الهواء يأخذ المقام الأول في أنواع التلوث المنتشر بمنطقة البحث ويعد المصنع هو المتهم الأول في هذا التلوث. جدول(ء): التكرارات والنسب المئوية لعينة الدراسة تبعاً للتساؤل تفتكر إيه مصادر تلوث الهواء؟

\begin{tabular}{|c|c|c|}
\hline$\%$ & العدد & المتغيرات \\
\hline$\varepsilon r, r$ & 70 & مداخن المصنح \\
\hline $9, r$ & $1 \leq$ & قمائن ومكامير الفحم \\
\hline$\Delta \wedge, V$ & $\Lambda \Lambda$ & الحرق المكثوف للقمامةٌ \\
\hline
\end{tabular}

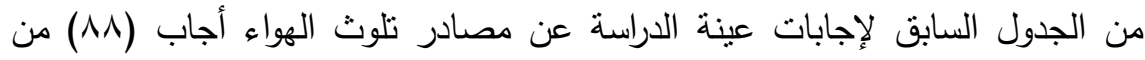

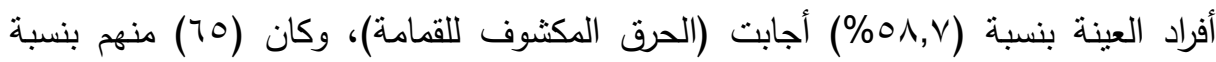

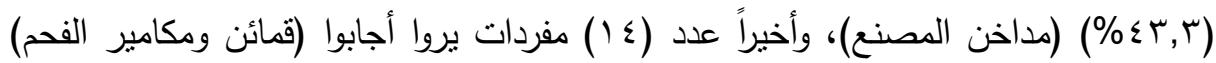

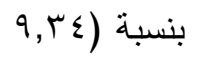

جدول(ه): التكرارات والنسب المئوية لعينة الدراسة تبعاً للنساؤل تقنكر إن التلوث ده بيظهر على العمال فى شكل إيه؟

\begin{tabular}{|c|c|c|}
\hline$\%$ & العدد & المتغيرات \\
\hline$\varepsilon \theta, r$ & 71 & آمراض صدرية \\
\hline $1,, \cdot$ & 10 & ضعف السمع \\
\hline$\Lambda, \vee$ & 14 & زيادة تكلفة الفرد بمعالجة التلوث \\
\hline$\varepsilon \wedge, \nu$ & VY & اخرى \\
\hline
\end{tabular}

من الجدول السابق لإجابات عينة الدراسة عن للتساؤل تفتكر ان التلوث ده بيظهر على

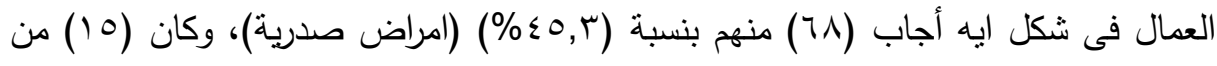

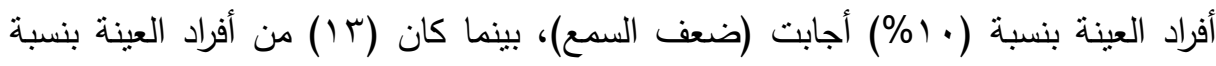
(\%^^,〉) 


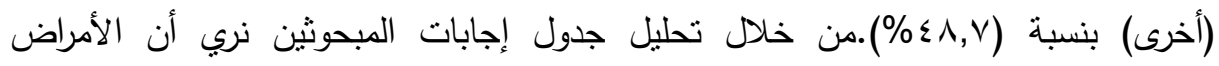

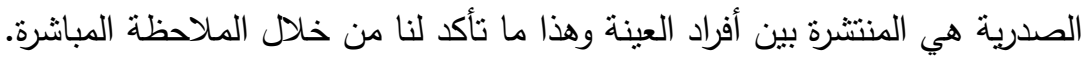

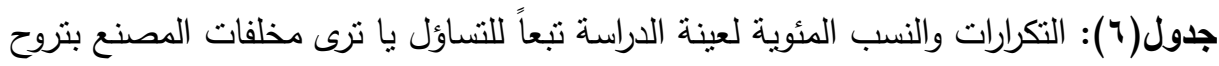

\begin{tabular}{|c|c|c|}
\hline$\%$ & العدد & المتفيرات \\
\hline$r, v$ & $\bar{\varepsilon}$ & في النيل \\
\hline$\theta, r$ & $\Lambda$ & تدفن في التزرية \\
\hline$r, \cdot$ & $r$ & تحرق في الهواء \\
\hline $9 \varepsilon, v$ & $1 \leqslant Y$ & منها في الاماكن المخصص \\
\hline
\end{tabular}

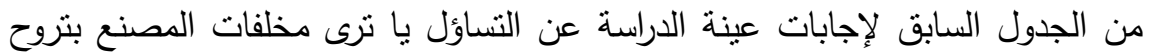

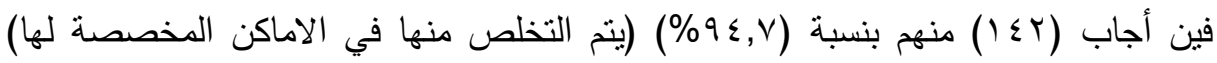

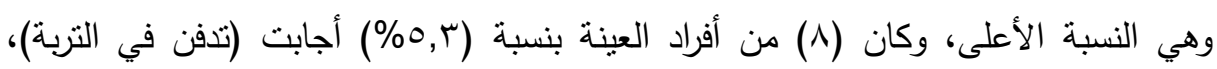

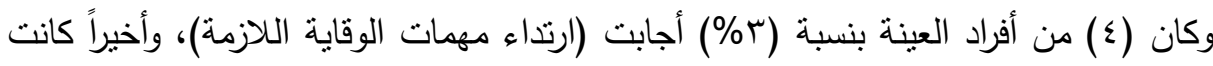

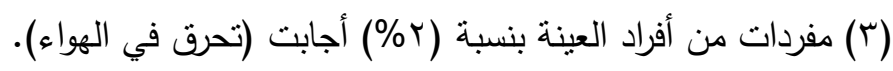

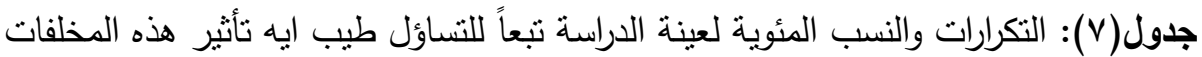

\begin{tabular}{|c|c|c|}
\hline$\%$ & العدد & 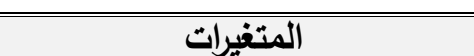 \\
\hline $1 \mu, \mu$ & r. & أصابة الانسان بأمراض سرطانية \\
\hline$\varepsilon, \cdot$ & 1 & تشويه الجنين في الحيوان والانسان \\
\hline YY,. & $r \mu$ & 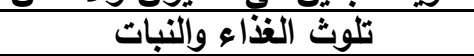 \\
\hline$\Lambda, \nu$ & 14 & تسمم الاسماك \\
\hline
\end{tabular}

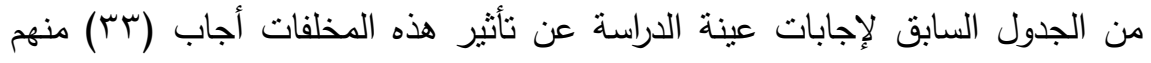

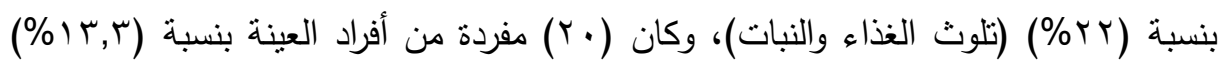

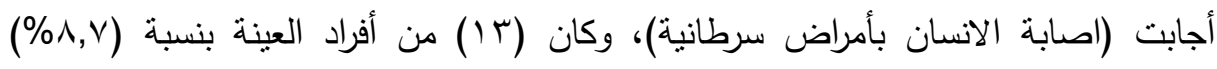

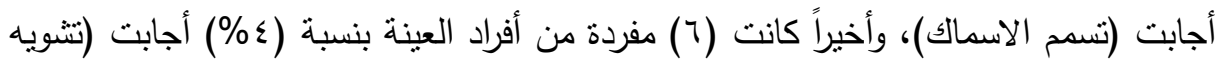

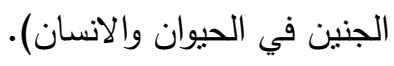


جدول(^): التكرارات والنسب المئوية لعينة الدراسة تبعاً للتساؤل طيب ايه مقترحاتك لـنع التلوث بالمخلفات؟

\begin{tabular}{|c|c|c|}
\hline$\%$ & العدد & المتغيرات \\
\hline$r \cdot, \cdot$ & $\$ 0$ & توعيةٌ الأفراد \\
\hline YV,r & $\sum 1$ & اعادة الاستخذام \\
\hline$\overline{r \cdot, \cdot}$ & \&0 & منع القاء المخلفات بالمياه \\
\hline$v 1, r$ & $1 \cdot v$ & تقليل المخلفات \\
\hline
\end{tabular}

من الجدول السابق لإجابات عينة الدراسة عن التساؤل طيب ايه مقترحاتكا لمنع التلوث

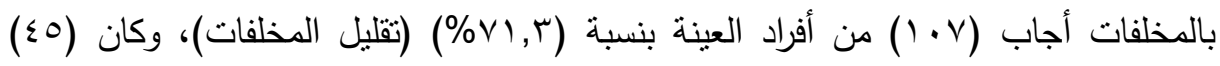

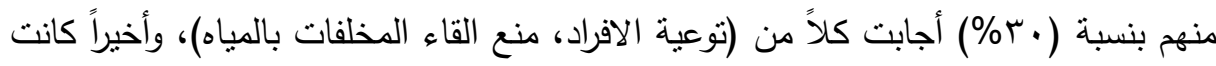

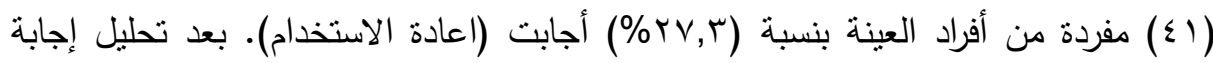
المبحوثين فنري أن هناك وعي بضرورة نقليل المخلفات من المنبع حيث أن ذلك يعود بنتائج إيجابية علي مسئولي المصنع من خلال نوفير النفقات للحد من التلوث والمجتمع المحيط

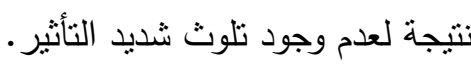

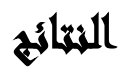

ا. تلوث الهواء الناجم عن مصنع سماد السوبر فوسفات بمنقباد- أسيوط يعتبر من أهم العوامل التي تساعد علي تلوث البيئة بالمنطقة. r. كثفت الدراسة عن انخفاض قيمة المحافظة علي البيئة. r. انتشار التلوث البيئي في مجتمع الدراسة منمثل في تلوث الهواء والمياه والضوضاء.

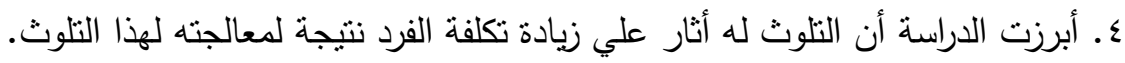
ه. انتشار المشروعات الصناعية داخل النطاق السكني أدي إلي تلوث البيئة. 7. محدودية اهتمام المصنع بتزويد العمال بأدوات مكافحة التلوث.

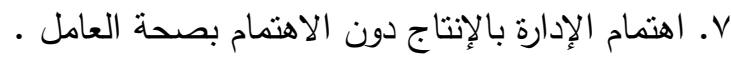
^. يؤدي نلوث كل من : الهواء والمباه والضوضاء في بيئة العمل الداخداء بإنلية والخارجية إلي الإصابة بالعديد من الأمراض وتعدد المشاكل الاجتماعية. 
9 . تعد صناعة السماد من أكثر الصناعات تلويثاً للبيئة. • 1. من أهم المشاكل البيئية التي تواجه العاملين داخل بيئة العمل علي التوالي : الأتربة

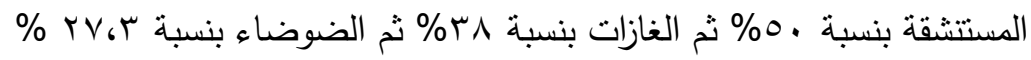

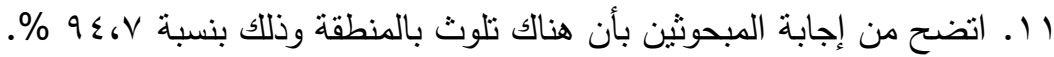

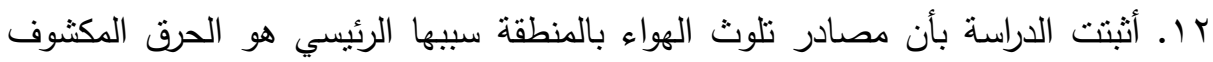

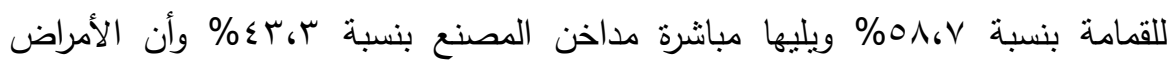

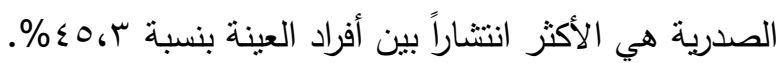

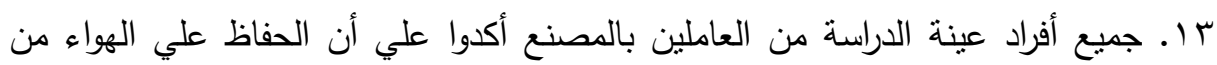

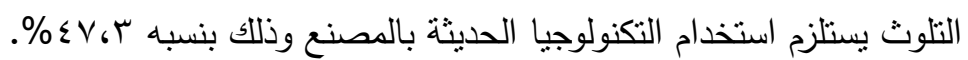

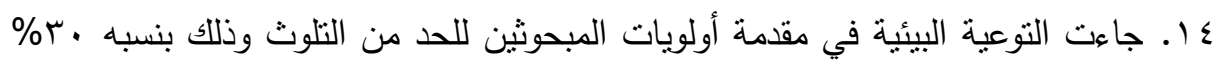

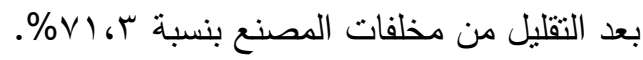

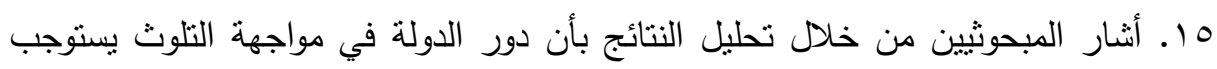

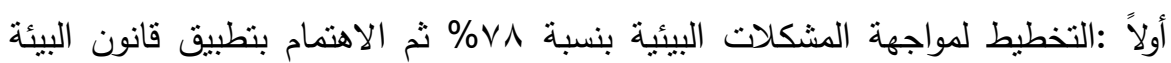

$$
\text { بنسبة 19r\%. }
$$

71 ـ ـ وجود علاقة معنوية دالة بين الخدمات الصحية المتوفرة بالمصنع وتلوث الهواء والمياه. V ا . وجود علاقة معنوية دالة بين الخدمات الصحية بالمصنع وشكل التلوث علي العمال. 1 ا ـ وجود علاقة معنوية غير دالة بين الخدمات الصحية المتوفرة بالمصنع وتلوث البيئة.

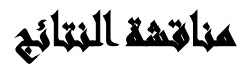

من خلال الدراسة التاريخية لصناعة الأسمدة الكيماوية تنين أنها من الصناعات التي

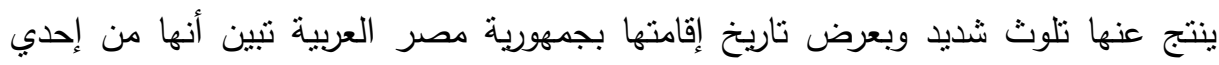
الصناعات القديمة التي أنشئت في مصر وذات تكنولوجيا قديمة لا نواكب التكنولوجيا الحديثة

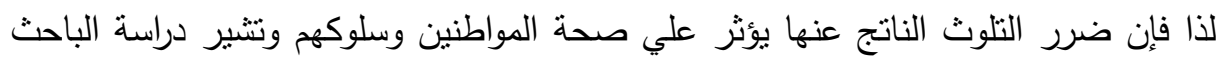

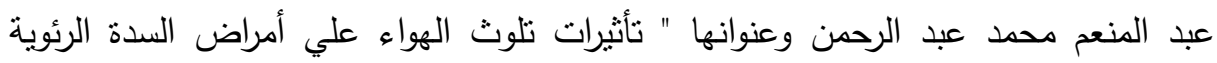
المزمنة" حيث أكد أن مصنع سماد منقباد يعد واحد من أهم مصادر تلوث الهواء الهماء بمحافظة 
أسيوط بالإضافة إلي تزايد عدد السكان وحدوث الزحف العمراني مما جعل مثل هذه المصانع

تتوسط الكتلة السكنية مما أثر بالسلب علي أهالي المناطق المجاورة للمصنع محل الدراسة. بالإضافة الي ذلك فهناك العديد من الدراسات السابقة التي تعرضت للمشكئلات التهات البيئية

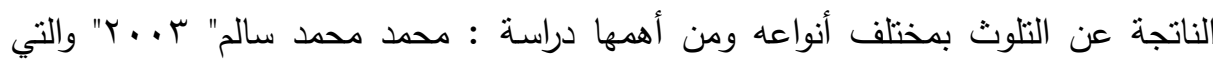
تهدف إلي القاء الضوء علي مظاهر التلوث الصناعي وأثاره الصحية علي البيئة والتعرف اهن علي مظاهر التلوث ومصادره وأنواعه وعلي مدي انتشار النلوث البيئي بالقاهره الكبري بصفة لئل

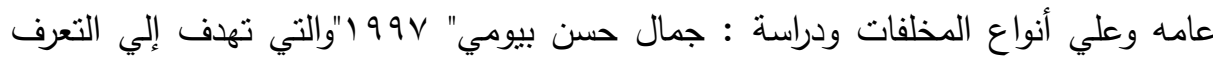
علي المشكلات البيئية التي تتتج عن الصناعة وتحديد آليات مكافحه التلوث الصناعي. من خلال الدراسة الميدانية والتحليل نبين أن كل النتائج التي توصلت إليها الدئه الدراسة مطابقة لما هو موجود علي أرض الواقع من خلال تأثز الأراضي الزراعية والمواثي وسكان

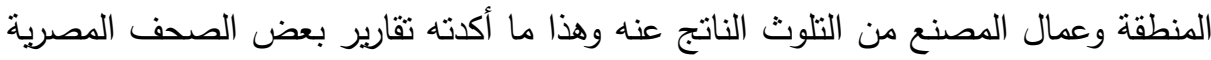

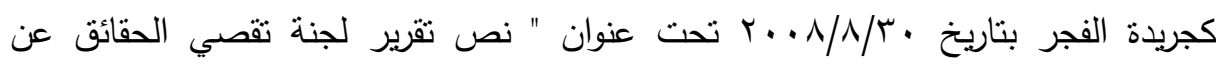
مخالفات مصنع سماد منقباد".

\section{اللغاسم}

وهذه النتائج تؤكد أن للتلوث أثز واضح علي صحة المواطنين بإلاضافة الي عدم اكتراث إدارة المصنع بأهمية الجانب البيئي وتباطؤ الجهات الرقابية بتطبيق مبدأ الإلزام والالتزام.

\section{اللموصياهت}

ا ـ تتديد الرقابة علي المخالفين لقانون البيئة والقوانين والقرارات ذات الصلة ونطبيق القوانين

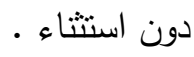
r. العمل علي جذب الجمعيات الأهليةلمساندة الأجزة الحكومية في ممارسة دوراً رقابياً وتفعيل ما ورد بشأنها بقانون البيئة المصري .

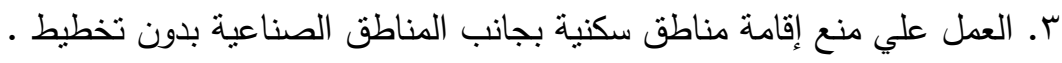


ـ ـ إيجاد حلول أخري للمساعد علي تطبيق قانون البيئة كفرض ضرائب مباشرة علي المصانع والأخذ بمبدأ الملوث يدفع الثمن.

ه. منع إقامةأي مشروع أو السير في اجراءات الترخيص إلا بعد عمل دراسة نقييم أثر بيئي ذات رؤية شاملة وخصوصاً مراعاة البعد الاجتماعي .

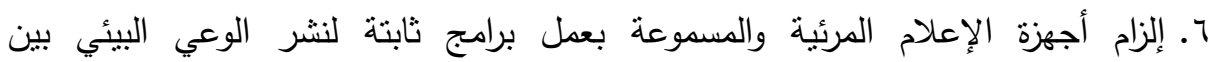

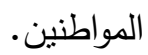

V. لابد من تخصيص وظائف عمل لأهالي المنطقة المجاورة للمصنع ومساعدة المجتمع المدني لإنشاء مراكز طبية متخصصة بالمنطقة. ^. الاتجاه إلي الانتاج الأنظف في الصناعة والحد من التلوث في كافة مجالات الصناعة.

\section{المراليم}

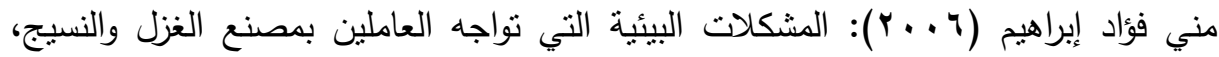

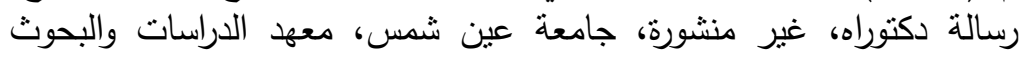

$$
\text { البيئية. }
$$

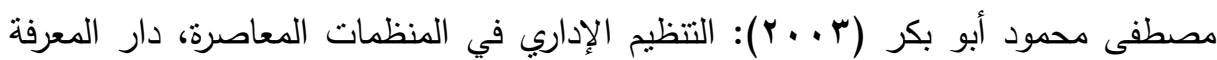

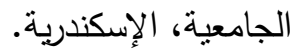

أحمد الجلاد(1 + . ץ): التتمية والبيئة في مصر ، الهيئة العامة. أحمد ماهر (991 (191): السلوك التتطيمى، دار المعرفة الجامعية، الإسكندرية.

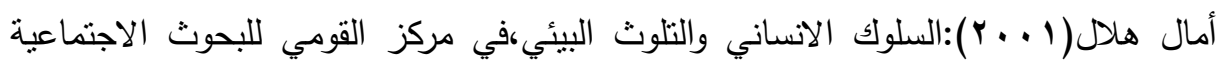
والجنائية،بحث التكلفة الإجتماعية لتلوث البيئة في مصر ،دراسات حول تلوث الإث البيئة ،التقرير الأول، القاهرة.

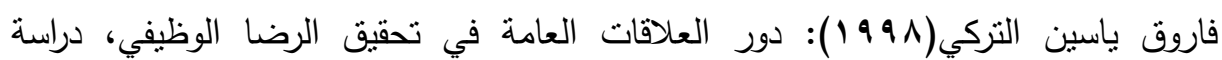

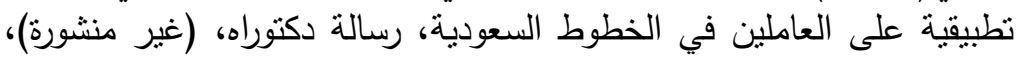
كلية الإعلام، جامعة القاهرة.

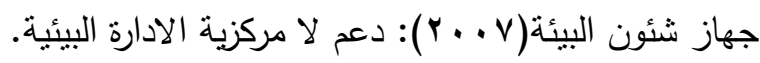


إيهاب صبيح محمد زريق(1 +. ب):العلاقات الصناعية وتحفيز الموظفين، دار الكتب الجامعية للنشر والتوزيع،القاهرة.

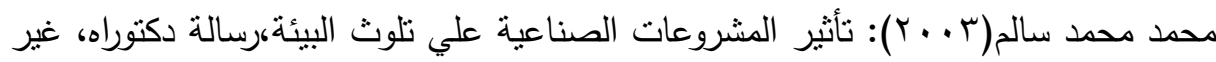

منشورة ، جامعة عين شمس، معهد الدراسات والبحوث البيئية.

مصلح الصالح(999 99 ) ): قاموس مصطلحات العلوم الاجتماعية ،دار عام الكتب ،الرياض.

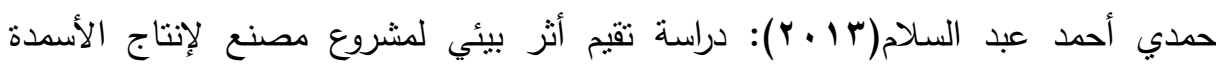

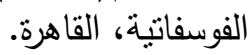

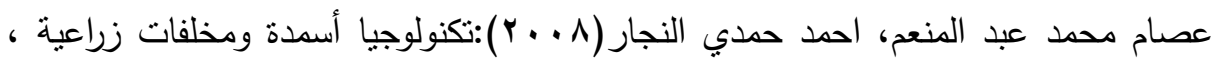
كلية الزراعة، جامعة عين شمس.

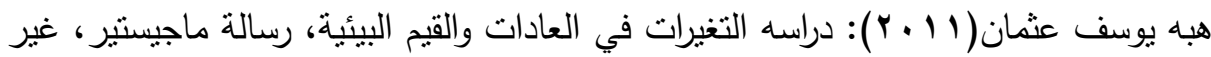
منشورة ، جامعة عين شمس، معهد الدراسات والبحوث البئ في البئية.

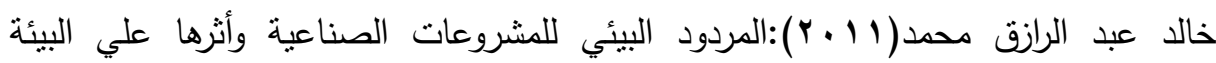

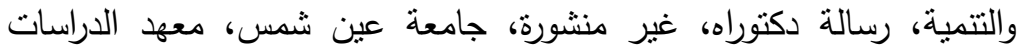
والبحوث البيئية

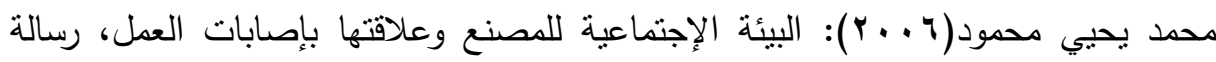
ماجيستير ،غير منشورة، جامعة عين شمس، معهد الدراسات والبحنة البحوث البيئية

أحمد سيد مصطفى(999 99 ( ) ): إدارة الموارد البشرية، دار الفجر للنشر والتوزيع، القاهرة.

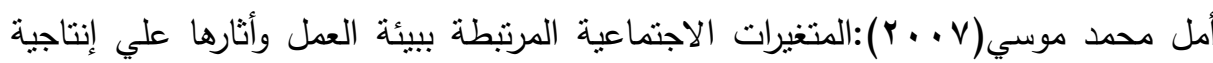

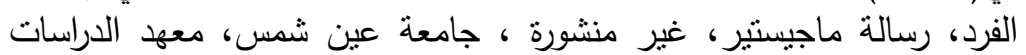

$$
\text { والبحوث البيئية. }
$$

Carole Boraiko: Exposure Assessment of Butyltin Manfacturing Workers Based on Concurrent Environmental and Biologyic al Monitoring,phd,Temple University,2003

Cote, S \& Heslin P: Job Satisfaction and Organizational commitment on Sleep Well's Seattle Branch, The Downtown Hotel, 2003, March 24. 
Cranny C.J. and others: Job satisfaction: how people feel about their and how it affect their performance Lexington New York, 1992, p.49. Willa M. and B.J. Walton: Balancing job satisfaction and performance quarum BKS. New York. 1993. p.p.317.

Lawernce Radican Francis:Aretrospective Chorot Study of Chronic Kidndey Diseacse in Workers Exposed to Trichloroethy Lene, Other Slovents,,phd,University of New Jersey,2004

Leland Cole Brain:The Social Constructionof Worksite Health And Safety,problem:How problems And Remedial Strategies Become Defined by Hazardous Waste Workers,phd, university of California-Los-Angeles,2003

Mayer G.W: public opinion measuring satisfaction with organization in journalismquarterly. Vol.(57), 1993, p.p. 772-778. 
مجلة العلوم البيئية

معهد الدراسات والبحوث البيئية - جامعة عين شمس البئ

\title{
THE HEALTHY AND SOCIAL CHANGES RESULTED FROM THE INDUSTRY OF FERTILIZER \\ A FIELD STUDY ABOUT THE WORKERS OF THE \\ INDUSTRIAL AND FINANCIAL COMPANY- MANQBAD FERTILIZER
}

Abdel Azim, S. S.(1); Al-Bukhary M. S. ${ }^{(2)}$ and Farag, M. F. ${ }^{(3)}$ 1) Faculty of Arts, Ain Shams University 2) Institute of Environmental Studies and Research, Ain Shams University 3) Egyption EnvironmentalAffairsAgency

\begin{abstract}
Growing concern for the environment and Qzaiaha- in the past Alojerh- clearly became capture the interest of developed and developing countries argue International reports that the third world is facing the biggest countries in the developed world environmental crisis and that the low economic conditions of those countries that are linked by low environmental conditions (Amel Hilal, 308.2001).

It began the need to highlight the most polluting industries to the global environment in general and the Egyptian environment in particular though few researchers have touched on this topic, so we had familiarity and knowledge in all aspects pertaining to phosphate fertilizers and pollution industry that produces them and how to confront it and to look at the need to develop and introduce modern technology in line with the production increase because of its paramount importance, especially in light of the water problem and the lack of silt on the other hand, lack of influence on the environmental and social system in pits study to identify the pollutants that result from the fertilizer industry and its effects on human health and the profile of the development of a global and local industry as well as the
\end{abstract}

$$
\text { المجلد السادس والثلاثون، الجزء الثالث، ديسمبر } 17 \text { ـ ب ا }
$$




$$
\text { صالح سليمان عبد العظيم وآخرون }
$$

importance of preparing a study assessing environmental and social impact of such industries.

So the trend in our research this finding workable solutions to eliminate the problem of pollution and the development of old industries and so we can say that environmental protection is no longer entertaining, but it is the duty of inevitable human Ali and China at the end of search circulate the recommendations in order to preserve the community of environmental pollution.

The main objective of this study is to demonstrate the environmental and social changes resulting from the Egyptian Financial and Industrial Company Bmnaqbad- Assiut what caused the damage to the workers inside the facility and residents near and reach their positive in dealing with the environment down to protect themselves and their lack of effect on productio.this study belongs to the descriptive studies to study the impact of pollution on health and society.He has chosen a researcher in this research social survey sample.

\section{The most important search results:}

-Air pollution from superphosphate fertilizer Bmnaqbad- Assiut factory is one of the most important factors that help the environment pollution in the region.

-The study revealed a decline in the value of preserving the environment.

-Spread of environmental pollution in the study population represented in the air, water and noise pollution.

-The study highlighted that pollution has implications for increasing the cost of an individual as a result of his handling of this pollution.

-The spread of industrial projects within the residential scale led to the pollution of the environment.

-Limited interest in the plant to provide workers with tools pollution control.

-Management attention to production without paying attention to worker health.

$$
\text { المجلد السادس والثناثون، الجزء الثالث، ديسمبر r } 1 \text { ـ ب }
$$


مجلة العلوم البيئية

معهد الدراسات والبحوث البيئية - جامعة عين شمس لئه

-Pollution leads all of the air, water and noise in the environment of internal and external work to the incidence of many diseases and multiple social problems. 